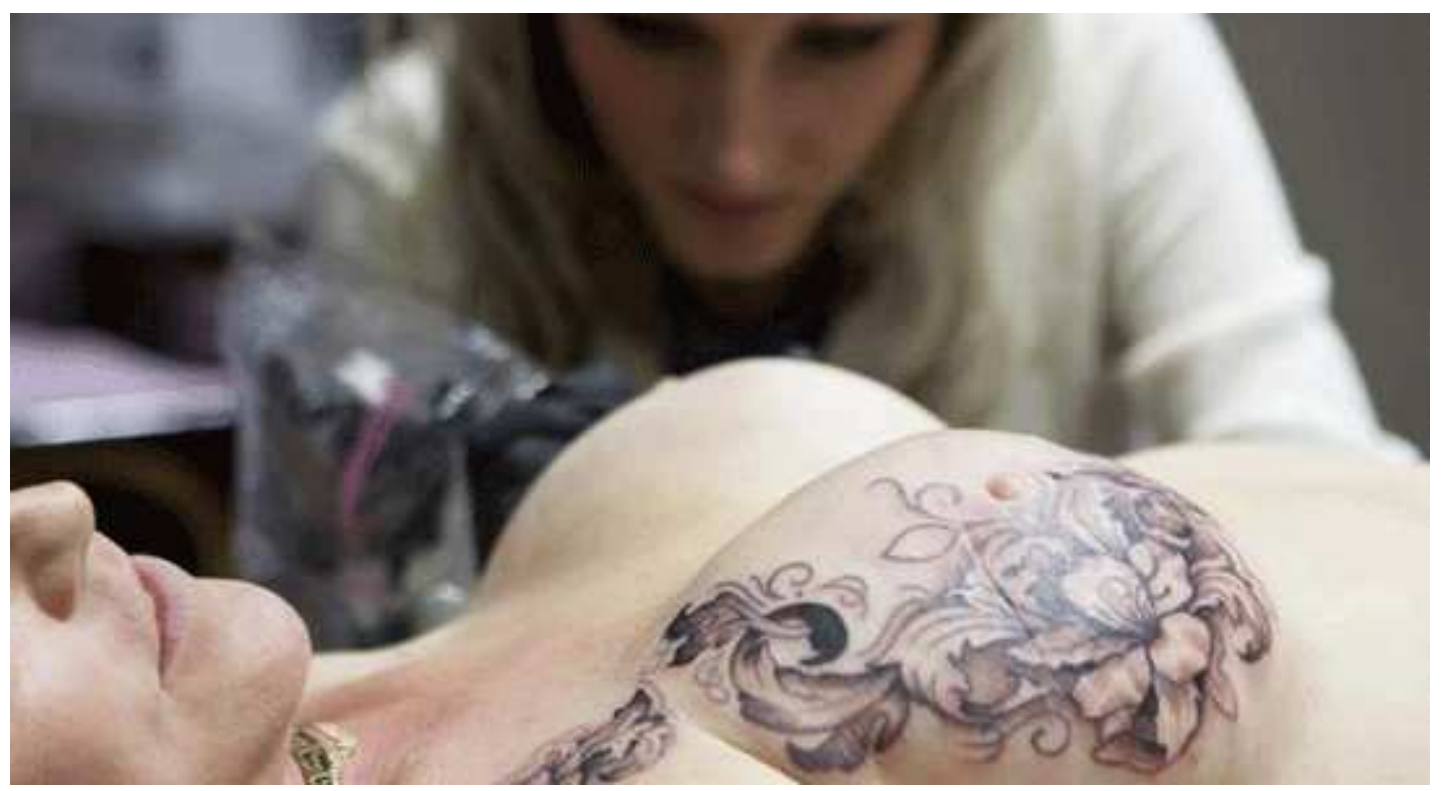

\title{
Sentidos do/no corpo interpelado pelo câncer de mama
}

Senses of / in nobody challenged by breast cancer

\author{
Lívia Fabiana Saço** \\ Eliana Lúcia Ferreira**
}

\section{Resumo}

A presente pesquisa teve como objeto o discurso de mulheres acometidas pelo câncer de mama e objetivou compreender de que maneira o ser mulher interpelado pelo câncer de mama se significa e/ou é significado corporalmente. Foi desenvolvida através da perspectiva teórica da Análise de Discurso em sua vertente francesa e apresentou seu Corpus constituído por 27 entrevistadas que passaram pela cirurgia da mama para a retirada do tumor. Observamos que as discursividades sobre o corpo expresso pela mulher interpelada pelo câncer de mama mostram um discurso social, evidenciando as marcas dos limites, das ambiguidades e das contradições presentes no desenvolvimento da doença e na feminilidade do ser mulher. A passagem pela doença produz novas formas de significação, novas organizações do dizer, novos processos de identificação, outras modalidades de subjetivação.

Palavras-chave: Mulher, mastectomia, corpo.

\begin{abstract}
This research has as object the speech of women affected by breast cancer and aimed to understand how the "Womanhood" challenged by breast cancer if means and/or bodily menaning is. Was developed through the theoretical perspective of discourse analysis in his shed and presented his French Corpus consists of 27 respondents who had surgery to remove the breast tumor. We observed that the discourses on the body expressed by women challenged by breast cancer shows a social discourse, showing the marks of bounds, the ambiguities and contradictions in the development of the disease andfemininity of"Womanhood". The passage by the disease produces new forms of meaning, say the new organizations, new processes of identification, other forms of subjectivity.

Keyword: Woman; mastectomy; body

\footnotetext{
Fisioterapeuta; mestre em Educação Física; Universidade Federal de Juiz de Fora. Endereço: Rua Santos Dumont, 335/1101, e-mail: assessoriapedagogica.gime@uab.ufjf.br.

** Educadora Física, doutora em Educação Física, Departamento de Fundamentos, UFJF. Email: assessoriapedagogica.gime@ uab.ufjf.br, Juiz de Fora, MG.
} 


\section{Introdução}

O câncer de mama é a neoplasia de maior ocorrência que atinge o sexo feminino, tanto em países desenvolvidos, quanto nos que estão em desenvolvimento (BRASIL, 2011), sua etiologia ainda é desconhecida, porém a sociedade atual, em um contexto geral, está muito exposta aos seus fatores de risco tais como: fumo, vida sedentária, dieta rica em gorduras e pobre em frutas e vegetais, alguns vírus como o da Hepatite B, Papiloma Vírus Humano (HPV) e fatores genéticos (JURBERG, GOUVEIA, BELISÁRIO, 2006; MARUYAMA, 2006; STEVEN et al., 2009).

Uma vez detectado o câncer, a mulher necessitará passar por vários procedimentos no processo de tratamento e, essas intervenções afetam não somente a célula maligna, como também as células de tecidos saudáveis, levando a uma série de debilitações, agudas e crônicas (SEIXAS; KESSLER; FRISON, 2010).

Segundo Park, Zlateva e Blank (2009), a experiência do viver com câncer envolve uma transformação física e psicológica que influi no autoconceito dos indivíduos, levando-se em conta o desenvolvimento de novas identidades.

Por se tratar de uma doença crônica, as questões psicológicas e comportamentais emergem associadas à vida dessas pessoas, uma vez que a doença não se resume a um estado orgânico diferenciado, não está isolada em órgãos ou tecidos; ela se entrelaça nas redes sociais, onde está inserida a pessoa doente, em que o universo social da mulher mastectomizada se reflete na construção de uma nova pessoa, com novas maneiras de ver, ser vista e sentir seu corpo. Como ser relacional, o doente não pode viver sua doença fora dos contextos sociais dos quais faz parte, e esses contextos vão se refletir na experiência do adoecer (AURELIANO, 2007).

$\mathrm{O}$ presente artigo tem como objeto o discurso de mulheres acometidas pelo câncer de mama e objetivou compreender de que maneira o ser mulher interpelado pelo câncer de mama se significa e/ou é significado corporalmente. Este nosso trabalho pretende contribuir com as discussões sobre a relação do ser mulher com o câncer, com o câncer de mama, consigo mesmo e com o corpo.

Observar o processo de significação do adoecer e toda a transformação corporal em decorrência do câncer de mama na vida das mulheres participantes da pesquisa nos colocou diante de subjetividades femininas. A subjetividade é um efeito-sujeito produzido a partir da relação entre as diferentes posições-sujeito nas distintas fases do 
câncer de mama. Já o processo de significação e significado referiu-se à inscriçãoidentificação da mulher com "O Câncer", do ser com câncer de mama consigo mesmo e a relação com o outro.

\section{Referencial Teórico e Metodologia}

Trabalhamos com o referencial teórico a Análise de Discurso de orientação francesa porque percebemos que nela se trabalha com as relações entre a língua, o sujeito e as práticas sociais de forma muito própria, não estanque, mas aberta aos efeitos de sentidos dos ditos, e também dos não ditos.

Por este tipo de estudo, se pode conhecer melhor o homem que por excelência significa a si e ao outro (ORLANDI, 2001, p. 15). Portanto, o objetivo desta pesquisa foi o de, através da Análise de Discurso, compreender, discursivamente, de que maneira o ser mulher interpelado pelo câncer de mama se significa e/ou é significado corporalmente.

Para realizar as análises das entrevistas mobilizamos diversos conceitos da análise de discurso, configurando para nós um "dispositivo de análise”. Segundo Orlandi (2007, p. 59), "analisar é compreender a ordem do discurso em questão" e, nessa perspectiva, a Análise do Discurso busca encontrar não o ideológico explícito ou implícito do texto, mas a maneira como o dito ou o não dito se significa.

Seguimos os procedimentos da Análise de Discurso que se detêm em certas marcas linguísticas para compreender o processo discursivo (ideológico) mais amplo inscrito nelas.

Nesta perspectiva, as marcas linguísticas com que trabalhamos foram os pronomes, os adjetivos e os advérbios, buscando compreender como eles foram sendo usados tanto em relação ao sujeito como em relação à doença. Essas marcas foram pontuadas pela maneira como os enunciados apresentaram as mesmas palavras temáticas sobre a doença no que se refere ao momento presente, à funcionalidade, às preocupações, às mudanças. Embora essas palavras inicialmente nos pareçam ser as mesmas, segundo Orlandi (2007), sabemos que, em relação ao sujeito, não são.

Para tanto, analisamos um corpus constituído por 27 entrevistas feitas com pacientes que passaram pela cirurgia da mama para a retirada do tumor. Todas realizam o tratamento no hospital Ascomcer na cidade de Juiz de Fora-MG, centro de referência em Oncologia, com finalidade do combate e a prevenção do câncer. Em 2010 foi 
habilitado pelo Ministério da Saúde como Unidade de Assistência de Alta Complexidade em Oncologia (UNACON).

Analisamos entrevistas gravadas, das quais foram transcritos os recortes mais significativos. Procuramos compreender como os discursos significam o corpo em diferentes formações discursivas e se reapresentam para os sujeitos, em sua produção de linguagem. No tocante à sua materialidade, tivemos de compreender os sentidos produzidos, ou melhor, tivemos de entender como é que o sujeito estava ali produzindo sentidos, porque o texto não produz sentidos em si mesmo e sim pelos sujeitos (FERREIRA, 2003).

Adiante, analisaremos a presença dessas discursividades, em suas marcas enunciativas, nas falas das mulheres pós-cirurgia da mama para a retirada do tumor.

\section{Sentidos do/no Corpo}

Segundo Ferreira (2005), interpretar quais são as mudanças corporais ocorridas pós-câncer é compreender como o sujeito se mostra ou não por intermédio dos processos de subjetivação, que não são totalmente visíveis, e, como, por meio do discurso, fornece-nos pistas/indícios para essa visibilidade.

No entanto, no processo de significação, esses sentidos não se constituem separados. Existe a relação da mulher com o câncer de mama, com o meio e o olhar com que essa mulher percebe sua cultura e a sociedade na qual vive.

O câncer de mama é entendido como uma doença crônica, sendo esta caracterizada por uma condição que requer longo tempo de cuidado e duração. A paciente necessita de um preparo mental para se adaptar à doença e ter precauções na vida, que envolvem estratégias, para lidar com os sintomas e enfrentar a mudança no estilo de vida, nas relações familiares e sociais, além de contínua e concomitante ação de prevenção primária, secundária e serviço de reabilitação (FREITAS; MENDES, 2007).

Sobre o novo papel a ser assumido pela mulher após o diagnóstico da doença para um novo ser doente de câncer, Vieira e Queiroz (2006) atentam para os enfrentamentos que as mulheres terão em seu modo de vida e suas relações interpessoais.

Sabe-se que o discurso sobre o câncer de mama já traz sentidos sobre a noção da doença e, consequentemente, já ocorre uma separação do sujeito com ele mesmo. Há 
uma censura que se impõe nessa relação. Essa censura não nasce com ele, mas se filia a seus sentidos. Essa filiação aos sentidos do câncer faz com que a pessoa tenha, em um primeiro momento, a associação com a morte, com a incapacidade, com a impossibilidade, com a debilidade. Isso ocorre porque o câncer já está significado na cultura brasileira, pois já existe um imaginário negativo do que é a doença, que vem por uma historicidade com seus significados.

Segundo Ferreira (2001), o discurso corporal é estruturado diferentemente da linguagem verbal. Por este motivo, estabeleceremos adiante a relação do discurso corporal dito pelo discurso verbal.

Nessa perspectiva, o significado do corpo no grupo das entrevistadas é ambivalente, pois os sentidos dados dependem das experiências pessoais vivenciadas e interpeladas por uma doença que afeta o biopsicossocial.

Quando falamos de discurso corporal, estamos destacando "partes do corpo" biológico, que possui um significado social além da sua própria funcionalidade.

Destacamos a seguir alguns recortes significativos das entrevistas, embasada em três perguntas principais: Como você está se sentindo nesse momento? Quais as principais mudanças ocorridas até o presente momento? Qual sua maior preocupação?

A mama está relacionada à nutrição física que a mãe proporciona ao lactente pelos seios, processo pelo qual a mãe estabelece contato com o filho e lhe proporciona não só o alimento, mas também o prazer e o acolhimento (SILVA, 2008). A extirpação da mama pode significar para essas mulheres a impossibilidade de permanecerem como acolhedoras e nutridoras (SILVA, 2008), ocasionando conflitos, sentimentos de rejeição e culpa pela perda da feminilidade (CONCEIÇÃO; LOPES, 2008). Estes autores acrescentam que a forma como a mama é vista em uma determinada sociedade contribui para sua maior valorização, influenciando, diretamente, o processo de estruturação da imagem corporal das mulheres.

Segundo Paiva e Goellner (2008), as mulheres, sem a mama, não conseguem se enquadrar nos padrões estéticos valorizados pela sociedade contemporânea. Esses sentimentos de rejeição, perda da feminilidade, valores estéticos e sociais mobilizam a direção de sentidos nestes recortes discursivos formulados pelas depoentes:

(...) se tivesse que fazer " $n$ " retalhos na minha mama me incomodaria menos do que o fato de perder (...) realizar a retirada completa (...) (S7).

A que mais marcou foi quando eu perdi meu peito e descobri que estava com câncer (...) Eu tinha medo de tirar a mama, mas não vou precisar estava com um pouquinho de medo, receio (...) porque é um pedaço da gente (...) (S15). 
Eu já tive um certo conflito interno por causa do seio, já pensei na reconstrução mas não vai ocorrer por causa de outros problemas. Eu aceito (...) (S20).

Tirei um nódulo e voltei em maio de 2005 (...) até este ano deu uma microcalcificação, assim... microscópica, deu que retornou e por preocupação irá fazer a mastectomia total por precaução, porém realizarei no mesmo momento a reconstrução (S7).

Nesses recortes, encontramos o conflito social/corporal, pois percebemos ambivalências e contradições nas condutas, uma vez que as mulheres demonstram o entendimento e a necessidade da cirurgia, porém enfatizam a reconstrução logo após a extirpação, sem deixar visível a ausência do seio. Marca-se a necessidade do visível (corpo) transpondo o invisível (câncer/doença), o fato de não visualizar o seu corpo mutilado ajuda a minimizar o processo do impacto social.

Segundo Ferreira (2003), o estigma, na sociedade brasileira, tem o sentido do discurso dominante, no qual o diferente tem de se subordinar ao esquema de uma lógica na culpa em si pela indiferença, levando à reprodução dos argumentos em que se apoiam a concepção da marca, constituindo formas de segregação e marginalização.

Quando as mulheres se veem desprovidas de uma parte do seu corpo, observado na regularidade da repetição da palavra "perda" e, nesse caso, especificamente a mama, o conflito interior aflora, o corpo é apresentado de forma diferenciada como algo incomum à realidade. É algo que amedronta, gera medo, reclusão, e os discursos mostram que as mulheres vivem um processo de construção de um ser não identificado por elas e procuram soluções reais e imaginárias, a mais próxima do ser anterior ao acontecido.

Muitas mulheres, apesar de relatarem incômodo em relação à falta da mama, não veem essa parte do corpo como o problema maior na imagem e na feminilidade, pois, muitas vezes, podem ser utilizados artifícios para não deixar essa visibilidade tão exposta. Uma das questões de incômodo maior presente nos discursos das mulheres após a mastectomia está relacionada com o linfedema.

Nas entrevistas, o linfedema é tratado com uma deformidade/negatividade do corpo somado à disfunção e limitação do membro homolateral à cirurgia: "Eu já tive um certo conflito interno por causa do seio e do inchaço do braço, já pensei na reconstrução, mas não vai ocorrer por causa de outros problemas. Eu aceito" (S21). 
Esse discurso de conflito entre o aspecto aparente e a limitação corporal repercute, constantemente, em sentidos da incapacidade, que, muitas vezes, é dito a partir do processo de conformação, mas não de aceitação da situação.

O diferente, o "anormal", sempre atraiu olhares, subjugando as mais diferentes especulações. Esta questão de anormalidade se torna visível a partir da queda do cabelo, advinda dos efeitos colaterais do tratamento da quimioterapia que, simbolicamente, deixa a mulher marcada no social com o negativo. Essa peculiaridade foi pontualmente destacada por todas as mulheres entrevistadas:

O cabelo que caiu me sinto meio envergonhada de cair (...) (S4).

A preocupação maior foi o cabelo, mas não foi preciso fazer a quimioterapia. Qualquer coisa que eu sinto já acho que a doença é o cabelo (...) ( S19).

(...) ele [o filho da entrevistada] também me deu problema quando meu cabelo começou a cair, ele não chegava perto de mim (...) (S2).

(...) o problema maior foi a careca, encontrei duas pessoas que riram de mim, mas aguentei (...) (S26).

A estigmatizaçao advinda do corpo imperfeito está presente em todas as relações sociais (FERREIRA, 2005); por isso, podemos afirmar que o "problema" estético no corpo da mulher com câncer é um problema cultural/social.

Embora as diferenças corporais sejam, muitas vezes, aparentes, observamos que a subjetividade dessas mulheres está inscrita em uma imagem/memória de um outro corpo. A subjetividade é estabelecida na ambiguidade do normal/anormal e isto é evidenciado na contradição do discurso verbal/corporal:

Eu tenho vergonha do meu corpo e de trocar de roupa perto das pessoas. Ficou bem diferente, por causa cicatriz. Quero acabar de fazer a reconstrução, voltar a ser do jeito que eu era antes, quando vou trocar de roupa perto de outra pessoa e ela fica olhando e perguntando (...) (S17).

Eu procuro me arrumar para ser como era antes, mas minhas roupas antigas não me servem mais, minha autoestima vai lá embaixo (...) (S17).

Não sou mais a que eu era antes (...) (S17).

A mulher com câncer de mama na trajetória do tratamento é transformada não somente biologicamente, mas refeita pelo processo social-histórico. O corpo afetado pelo câncer traz consigo agora as marcas de um "um outro corpo que se digladia com a rememoração do que já foi e com as peculiaridades que o singularizam e que, às vezes, são negadas em busca do corpo anterior ao processo cirúrgico. 
Corpos diferenciados da normalidade social proclamam uma urgência de experimentar vivências corporais e de sobreviver físico e socialmente. É uma espécie de necessidade não apenas de encontrar um modelo de vida diferente, mas de buscar, a partir do contraste histórico entre uma identidade mais definida, uma nova forma de organização para o que já existia (FERREIRA, 2005).

Outra questão presente no discurso corporal é a questão da "Dor". Segundo Miceli (2009) e Shamley (2007), a percepção da dor possui uma visão multidimensional, e a modulação da dimensão fisiológica da dor é influenciada pelas dimensões sensorial, emocional, comportamental e cognitiva.

Sentimentos e sensações de dor vão aflorando ao curso da história da doença e de seu possível prognóstico; esta aparece imbuída de significados representativos na individualidade de cada ser:

Eu sentia dor quando eu estava com o peito, mas agora que tirou eu não sinto mais nada, só se pegar muito peso (...) (S15).

Sentindo bem, sentindo uma dor no braço. Dói muito, depois da cirurgia (...) (S23).

Tem dia que eu fico um pouco cansada, desanimada, com o corpo dolorido, a dor anda no meu corpo (...) (S8).

Dores de cabeça (...) e eu acho (...) que pode ser alguma coisa vindo da mama (...) ( S10).

A que mais marcou foi quando eu perdi meu peito e descobri que estava com câncer (...) aí doeu (...) [CHORO] (...) (S15).

$\mathrm{Na}$ transformação da mulher para uma mulher com câncer de mama, são percebidas cicatrizes não somente físicas, mas também psicológicas, afetando sua personalidade.

Todas estas "marcas corporais" que afetam, significativamente, as mulheres constituem-se em cicatrizes visíveis/invisíveis, palpáveis/(in)palpáveis, fazendo parte desse Ser agora transformado pela doença, transformação nos planos físico, social e psicológico, como podemos observar abaixo:

O centro cirúrgico me incomoda profundamente. Aquele momento da cirurgia me deixa ansiosa, me incomoda profundamente. O momento da anestesia é o pior, nem o antes nem o depois. A anestesia me deixou sequela do processo da outra cirurgia que eu tive que ficar respirando na máscara (...) foi angustiante (S7).

Essa porcaria voltar, não de me tirar mais uma parte do corpo, mas de me impedir de viver (...) (S21).

Foi difícil colocar a roupa e ver aquele lado vazio (...) (S19). 
As cicatrizes transpostas aos corpos nesse percurso poderão ser minimizadas com medidas sociais de educação e acesso a informações, além de esclarecimentos sobre a doença, conhecimento do corpo e acesso às redes de saúde, onde as mulheres poderão buscar atendimento.

Para tal, é preciso, a todo momento, questionar os efeitos sociais presentes na discursividade histórica do câncer. Desse modo, perante essa desorganização, a fim de criar novos movimentos, tanto no sujeito com câncer quanto naqueles que o cercam, é necessário criar nessa relação laços de identificação.

É preciso que o sujeito com câncer de mama se posicione como sujeito no momento vivenciado em razão da doença e que o outro estabeleça com ele uma relação de identificação tal que permita vê-lo não restritivamente como alguém que carrega uma doença, mas como um sujeito com singularidades como todos têm e são, deixando de ser significado apenas pela doença que nesse caso específico se marca no corpo, se expõe.

Socialmente, a mulher é vista como um ser determinado a cuidar dos outros, pois, geralmente, é a pessoa designada para cuidar dos filhos, porque é ela quem os gera. A mulher passa a ter uma determinação social de guardiã passiva do bem-estar familiar e, às vezes, esquece-se de si mesma (FABRO; MONTRONE; SANTOS, 2008), conforme se pode verificar nos seguintes relatos:

Tô preocupada por causa do filho que ficou em casa, meu esposo está passando mal também, tô meio tensa, tô preocupada .... mais preocupada com eles (S1);

Mediante ao tratamento que me foi disponível, minha preocupação maior é com o filho menor que é adotado (S2);

Nesse período da quimioterapia eu já conscientizei mais, pois eu quero saúde e vida porque assim...por causa do meu filho, por causa de mim... né (S2);

(...) mas de me impedir de viver, curtir meus filhos. Fico muito assustada. (S21)

Essa determinação social, mesmo no embate que a resiste, é fortemente verificada no recorte seguinte de (S2):

(...) eu me mantinha de pé até a hora que ele ia prá escola, entendeu?! deitava depois; e (...) eu não tava saindo muito por causa que perdi a sensibilidade nos pés e nas mãos então tava dificultando eu andar (...) ele falou assim (...) oh, mãe, eu tô tão feliz, tão feliz, sabe por quê? Porque você tá podendo sair comigo (...). Eu tento reagir por mim mesma. Um ano atrás também tive que cuidar do meu irmão que também estava com câncer, então eu abracei a causa. Por um lado, também foi uma reciclagem na minha vida totalmente diferente (...) pois comecei a cuidar mais de mim (...) antes eu cuidava só dos outros. 
Observamos que a mãe significa sua função/imagem de proteção desmoronando para o filho, sendo esse também o processo que ela está vivenciando, formando-se um duplo desmoronamento, dela e para ela, na resistência. Esse processo pode servir como sentido e motivação para o enfrentamento e suporte para a readaptação de sua posição social face à magnitude da identidade do ser mulher.

O amparo e a proteção, nesse momento de vida, são essenciais para a confiança e força na caminhada árdua que se faz por toda a trajetória do câncer. Visando ao retorno do espaço, papéis e atividades, o suporte presente nos familiares, amigos, bem como nas pessoas próximas, ajudará a mulher a se sentir mais integrada, aceita, atuante, em uma atitude menos passiva e de menor dependência (CARDOSO, 2009), como se pode verificar nos seguintes recortes:

Meus irmãos e sobrinhos me dão muita coragem (S19);

Tenho muito apoio familiar, meu marido é maravilhoso (S8);

[...] meu marido, amigos, vizinhos e médicos me ajudaram, você se sente amparada (S16).

Todas essas questões afetam, diretamente, a relação corpo/trabalho, capacidade/(in)capacidade, produtividade/(in)produtividade e, devido à funcionalidade do membro superior apresentar-se comprometida, como já visto na primeira parte desta pesquisa, essa debilidade acarreta em alterações funcionais, comprometendo os indivíduos em sua posição de independência, e estes vão se sentir mais vulneráveis, em uma posição mais "paciente" da vida (CARDOSO, 2009).

Este processo de significação está presente nos próximos recortes discursivos das entrevistas em que a relação com o trabalho, a previdência do Estado e os cuidados domésticos estão em embate:

(...) O INSS já me liberou e o meu emprego não quer me aceitar, pois eu ainda estou fazendo fisioterapia, estou achando que estão acontecendo coisas ruins também (...) em relação ao tratamento (...) (S10).

(...) No momento da doença, eu estava doente e não falei nada para ninguém (...) e eles (soluço) me mandaram embora (...) (S10).

(...) Posso ser sincera?! Esse dinheiro aí é o que mais quero e voltar pra casa e cuidar do meu marido, eu já fiquei muito. Pegando esse dinheiro, eu ia ajudar minha irmã e voltar para casa, mas não vou abandonar aqui (S15).

(...) depois da cirurgia interferiu muito no meu trabalho, não posso pegar peso, andar muito, sinto muita dor e não posso fazer quase nada (S23). 
(...) muita coisa que eu fazia eu não posso fazer por causa do braço, do caroço não posso pegar peso, eu tinha atividade mais corrida e agora tem que ser mais devagar, isso que mudou (S1).

Se, por um lado, a previdência é significado como amparo nesse momento, um suporte do Estado, por outro há uma projeção de desamparo para lidar com a vida e as limitações do corpo. No recorte seguinte, encontramos pistas sobre a transformação da mulher após todo o percurso em razão da doença, que a transformou em outra mulher, com outra identidade. E, nesse processo de busca de uma auto-identidade, se isola: “(...) Prá falar a verdade, eu queria trabalhar assim (...) trabalhar sozinha (...) não queria voltar para o meu trabalho não (...) (CHORO)” (S10).

\section{Considerações Finais}

Observamos que as discursividades sobre o corpo expressas pela mulher interpelada pelo câncer de mama mostram um discurso que vai além do plano físico, se entrelaça nas redes sociais evidenciando as marcas dos limites, das ambiguidades e das contradições presentes no desenvolvimento da doença e na feminilidade do ser mulher.

As marcas incorporadas no/do corpo na presença da extirpação, da alopecia, do linfedema, da dor, transformam os sentidos, silenciam, ausentam.

O diferente, o anormal - estigmatiza, isola, impotencializa - e assim, ainda doente(?), curada(?), nessa passagem pelo desconhecido se ressignifica, se reorganiza, se subjetiva, se reergue.

\section{Bibliografia:}

ASCOMCER. Histórico Hospital Ascomcer (2011). Disponível em: <http://www.ascomcer.com.br/frmExibirConteudo.aspx?id=3>. Acesso em: $18 \mathrm{dez}$. 2011.

AURELIANO, W. A. 2007. Vênus Revisitada: negociações sobre o corpo na experiência do câncer de mama. Barbarói, São Caetano do Sul, v. 27, p. 107-129, jul./dez.

CARDOSO, F. S. 2009. Entre silêncios, sussurros e gritos: o corpo feminino atravessado pelo câncer de mama. 2009. 126 f. Dissertação (Mestrado em Educação Física) - Faculdade de Educação Física, Universidade Federal de Juiz de Fora , Juiz de Fora. 
CONCEIÇÃO, L. L.; LOPES, R. L. M. 2008. O cotidiano de mulheres mastectomizadas: do diagnóstico à quimioterapia. Revista de Enfermagem UERJ, Rio de Janeiro, v. 16, n. 1, p. 26-31.

FABBRO, M.R.C; MONTRONE, A.V.G; SANTOS, S. dos. 2010. Percepções, conhecimentos e vivências de mulheres com câncer de mama. Revista Enfermagem, UERJ, Rio de Janeiro, v. 16, n. 4, p. 532-537, out./dez. 2008. Disponível em:

<http://lildbi.bireme.br/lildbi/docsonline/lilacs/20090500/370_v16n4a13.pdf>. Acesso em: 20 dez.

FERREIRA, E. L. 2003. Corpo-movimento-deficiência: as formas dos discursos da/na dança em cadeira de rodas e seus processos de significação. 2003. 268 f. Tese (Doutorado em Educação Física) - Faculdade de Educação Física, Universidade Estadual de Campinas, Campinas..

Corpo-Movimento-Deficiência: as formas dos discursos da/na dança em cadeira de rodas e seus processos de significação.2005. Juiz de Fora: CBDCR, 2005.

FERREIRA, E. L.; ORLANDI, E.P. 2001. O discurso corporal atravessado pela dança em cadeira de rodas. In: ORLANDI, E. P. (Org.). Cidade atravessada: os sentidos públicos no espaço urbano. Campinas: Pontes, v. 1, p. 1-190.

FREITAS, S. R. Qualidade de vida, satisfação com a cirurgia e morbidade no ombro e braço de mulheres com câncer de mama submetidas à quadrantectomia ou à mastectomia com reconstrução imediata. Revista Brasileira de Ginecologia e Obstetrícia, Rio de Janeiro, v. 32, n. 2, p. 99-108, fev. 2010.

JURBERG, C.; GOUVEIA, M.E.; BELISÁRIO, C. Na mira do câncer: o papel da mídia brasileira. Revista Brasileira de Cancerologia, Rio de Janeiro, v. 52, n. 2, p. 139-146, abr./jun. 2006.

MICELI, A.V.P. Laços e nós: a comunicação na relação médico-paciente com câncer e dor crônica. 2009. 127 f. Dissertação (Mestrado em Saúde Coletiva) - Instituto de Medicina Social/UERJ, Rio de Janeiro, 2009. Disponível em: <http://www.tesesims.uerj.br/lildbi/docsonline/pdf/miceli_ana.pdf>. Acesso em: 20 jul. 2010.

ORLANDI, E. P. 2001. A desorganização cotidiana. In: Escritos $\mathbf{n}^{0}$ 1: percursos sociais e sentidos nas cidades. Labeurb/Nudecri, Unicamp. p. 3-10.

2001. Discurso e texto: formulação e circulação dos sentidos. Campinas, SP: Pontes.

2007. Análise de Discurso: princípios e procedimentos. Campinas, SP: Pontes.

PAIVA, L. L.; GOELLNER, S. V. Reinventando a vida: um estudo qualitativo sobre os significados culturais atribuídos à reconstrução corporal de amputados mediante a protetização. Interface - Comunicação, Saúde, Educação, Universidade Estadual Paulista Júlio de Mesquita Filho, São Paulo, v. 12, n. 26, p. 485-497, jul./set. 2008. 
PARK, L. C.; ZLATEVA, L.; BLANK, O. T. Self-identity After Cancer: "Survivor", "Victim", "Patient", and "Person with Cancer". Journal of General International Medicine, Heidelberg, v. 24, n. 2, p. 430-435, Nov. 2009.

SEIXAS, R. J.; KESSLER, A.; FRISON, V.B. Atividade física e qualidade de vida em pacientes oncológicos durante o período de tratamento quimioterápico. Revista Brasileira de Cancerologia, Rio de Janeiro, v. 56, n. 3, p. 321-330, jul./set., 2010.

SHAMLEY, D.R. et al. Changes in shoulder muscle size and activity following treatment for breast cancer. Breast Cancer Research Treatment, Boston,v. 106, p. 1927, Apr. 2007.

SILVA, L. C. Câncer de mama e sofrimento psicológico: aspectos relacionados ao feminino. Psicologia em Estudo, Maringá, v. 13, n. 2, p. 231-237, abr./jun. 2008.

VIEIRA, C.P.; QUEIROZ, M.S. Representações sociais sobre o câncer feminino: vivência e contexto institucional. Psicologia e Sociedade, Porto Alegre, v. 18, p. 63-70, jan./abr. 2006. 
Para citar essa obra:

SAÇO, Lívia Fabiana; FERREIRA, Eliana Lúcia. Sentidos do/no corpo interpelado pelo câncer de mama. RUA [online]. 2013, no. 19. Volume 1 - ISSN 1413-2109

Consultada no Portal Labeurb - Revista do Laboratório de Estudos Urbanos do Núcleo de Desenvolvimento da Criatividade

http://www.labeurb.unicamp.br/rua/

Capa: ROSE, David. Disponível em: http://pinterest.com/pin/221802350370147425/

Laboratório de Estudos Urbanos - LABEURB

Núcleo de Desenvolvimento da Criatividade - NUDECRI

Universidade Estadual de Campinas - UNICAMP

http://www.labeurb.unicamp.br/

Endereço:

LABEURB - LABORATÓRIO DE ESTUDOS URBANOS

UNICAMP/COCEN / NUDECRI

CAIXA POSTAL 6166

Campinas/SP - Brasil

CEP 13083-892

Fone/ Fax: (19) 3521-7900

Contato: http://www.labeurb.unicamp.br/contato 